\title{
The Characteristics of Limestone and Anthracite Coal as Filter Media in Treating Pollutants from Groundwater
}

\author{
N. A. Akbar, H. A. Aziz, and M. N. Adlan
}

\begin{abstract}
The performance of limestone and anthracite coal were evaluated for the removal of pollutants from groundwater. The physical and chemical properties of two filter materials were characterised through X-Ray diffraction (XRD), X-Ray fluorescence (XRF), field emission scanning electron microscopy (FESEM) and Fourier transform infrared spectroscopy (FTIR). XRD analysis showed that the main peaks of calcite $\left(\mathrm{CaCO}_{3}\right)$ are the predominant phase of limestone, whereas quartz and graphite are the crystalline phase of anthracite coal. The presence of calcium oxide $(\mathrm{CaO})$ as the major composition indicated that limestone demonstrates a good ability for cation exchange. FTIR spectrum analysis showed that the functional groups present on the limestone surface are mostly hydrophilic groups, and anthracite exhibits hydrophobic characteristic. Limestone has the potential to adsorb heavy metal pollutants, whereas anthracite has the capability to adsorb organic pollutants. Therefore, the two filter materials can be used as alternatives to remove pollutants in treating groundwater.
\end{abstract}

Index Terms-Anthracite coal, filter media, groundwater, limestone.

\section{INTRODUCTION}

A filter material is a porous material placed in a filter column that separates the liquid and suspended particles and changes the water quality after flowing through the media. At present, sand [1], gravel, anthracite coal [2] and granular activated carbon [3] are the filter media commonly used in drinking water treatment plants (WTPs). Chaudhry et al., (2016) indicated that sand can remove heavy metals by coating the sand with $\mathrm{Fe}$ and $\mathrm{Mn}$ oxide [4]. This metal-based additive improves the performance of sand filter by increasing the surface area and its capability to remove heavy metals. Previous studies have proven that the utilisation of raw limestone as filter material is effective in removing heavy metals [5]-[9]. Aziz et al., (2001) reported that limestone has high carbonate content creating an alkaline condition for water samples [6]. An increase in $\mathrm{pH}$ may increase the removal of heavy metal ions in the water sample. Limestone with a rough surface provides solid contact to the low concentration of metal ions through chemisorption and

Manuscript received June 12, 2020; revised December 14, 2020.

N. A. Akbar is with the Universiti Teknologi MARA, Cawangan Pulau Pinang, 13500 Permatang Pauh, Penang, Malaysia (e-mail: norazliza049@uitm.edu.my).

H. A. Aziz was with Universiti Sains Malaysia, 14300 Nibong Tebal, Penang, Malaysia (e-mail: cehamidi@usm.my).

M. N. Adlan is with the School of Civil Engineering, Universiti Sains Malaysia, 14300 Nibong Tebal, Penang, Malaysia (e-mail: cenordin@usm.my). improves flocculation of Mn precipitates [10].

Since 1935, the state of Kelantan has fully established potable and drinking water consumption from groundwater. There were about $75 \%$ of the population in Kelantan that consume groundwater for domestic water supply, agricultural and human activities. However, the major portion of groundwater around Kelantan contains high concentration of $\mathrm{Fe}$, which is above Malaysia Drinking Water Quality Standard [11]. Ozonation followed by post filtration method using anthracite coal has been applied at Pintu Geng WTP since 2013. Anthracite coal was imported from the United Kingdom, placed on the top layer of sand filter and traps large particles when the water comes in contact with the media during filtration. Shi et al., (2011) reported that anthracite contains the highest carbon content ( $90 \%$ to $100 \%$ ) compared with lignite (60\% to $75 \%$ ) and hard bituminous coal (80\% to 90\%) [12]. Apart from having the highest carbon content, it has extremely low impurities. In this study, limestone and anthracite were selected as alternative filter materials in a WTP.

The efficiency of a WTP in removing various types of pollutants depends on the effectiveness of the filter material placed in the filtration column. The filter material should be characterised to assess its compositions, surface morphology, and functional groups. A physical characteristic analysis includes surface structure and morphology, Brunauer-Emmett-Teller surface area and pore size, and chemical characteristic analysis includes functional group and chemical composition through XRD and XRF analyses [13]. FESEM is a magnification tool used to detect the microstructure, microcracks and mineral composition of a filter material [14]. FTIR is a technique widely used to identify the organic constituents of a geomaterial. This technique can differentiate the organic and inorganic functional groups. It can distinguish between aliphatic and aromatic carbon and hydrogen. XRD identifies the phases and determine the amounts of minerals present in a sample, and XRF measures the elemental compositions in a sample.

This study aimed to identify the potential of selected filter materials, namely, limestone and anthracite, to improve the quality of contaminated groundwater. The characteristics and properties of filter materials prior to their application in column filtration were investigated.

\section{Methodology}

This section explains the methodology used in the present study. The selected filter materials and characteristic analysis are discussed.

\section{A. Preparation of Filter Media}


The limestone used in this study was obtained from a marble industry located in Ipoh, Perak, whereas anthracite coal was purchased from Malaysian Coal and Minerals Corporation Sdn Bhd located at Gebeng, Kuantan Pahang. The two filter materials were sieved to pass through an aperture size of $1.18 \mathrm{~mm}$ and retain in $2 \mathrm{~mm}$ size. The selected size of anthracite media is based on the effective anthracite size from $1.4 \mathrm{~mm}$ to $2.5 \mathrm{~mm}$, which is used as the filter medium at the Pintu Geng WTP, Kelantan, Malaysia.

\section{B. Characterization of the Filter Media}

The characteristics of limestone and anthracite coal filter materials were determined in terms of elemental compositions, surface morphology and functional groups. Various analyses, including XRD, XRF, FESEM and FTIR, were conducted at the School of Material Engineering Laboratory, Universiti Sains Malaysia.

\section{1) X-ray diffraction $(X R D)$}

Analysis was conducted using a Bruker D8 Advance X-ray diffractometer. The two materials were grounded to fine particle size $(<0.75 \mu \mathrm{m})$ for preparing the samples using mortar and pestle. Powdered sample $(1 \mathrm{~g})$ was placed in an intense X-ray beam, and a pattern from X-ray diffraction intensities of $2 \theta$ was produced. The minerals in the sample were identified by scanning at an angle of $2 \theta$ and comparing with the standard reference patterns.

\section{2) $X$-ray fluorescence $(X R F)$}

$\mathrm{XRF}$ is an instrument used to determine the chemical compositions of a material. The energy absorption of the individual atoms of the sample was confirmed using an XRF spectrometer (RIX 3000, Rigaku). Approximately $25 \mathrm{~g}$ of limestone powder was pulverised into a fine powder $(0.75$ $\mu \mathrm{m})$, whereas anthracite powder was mixed with a fibrous cellulose powder (CF11) to act as a binder for spectroscopy analysis. The standard procedure of elemental analysis was performed in accordance to American Society for Testing and Materials (ASTM) E1621-05 standard.

\section{3) Fourier transform infrared (FT-IR)}

The functional group and chemical compound of the materials were analysed using a Perkin Elmer 2000 Fourier transform infrared spectrometer in accordance with the ASTM E1252-98 standard. The FTIR instrument generates an infrared absorption spectrum to produce the profile spectra and detects the chemical bonds of the sample. Approximately $2-3 \mathrm{mg}$ of the fine media $(<75 \mu \mathrm{m})$ dry sample was mixed with $200 \mathrm{mg}$ of potassium bromide. Then, the mixture was ground into fine powder using impact mortar and pestle. The mixture sample was uniformly transferred into the cylinder bore at a pressure of 10 tons. Then, a thin film pellet of the sample was produced and inserted into the sample compartment for scanning using a computerised FTIR machine and analysed on Spectrum version 5.0.2. The spectrum was displayed on the screen, where the peak indicates the functional group of the sample. The peak of the profile spectra was used to analyse the functional groups contained in the sample on the basis of infrared spectroscopy absorption table.

4) Field emission scanning electron microscopy (FESEM) analysis
FESEM is a magnification tool that scans the image of a sample to produce its surface morphology and composition using a Zeiss Ultra-35 VP scanning electron microscope. In this study, limestone and anthracite, with particle size between $1.18 \mathrm{~mm}$ to $2 \mathrm{~mm}$, were rigidly mounted to a specimen holder. The sample was coated with a thin layer of gold $(1.5-3.0 \mathrm{~nm})$ through spun coating to prevent charging of the sample when electron is emitted. Then, the sample holder was placed into the mounting holes and scanned to obtain the images. The sample can be detected by adjusting the magnification to the range of $500 \mathrm{KX}$ to $10 \mathrm{KX}$ on the basis of the ASTM E1951-02 standard.

\section{RESUlT AND DISCUSSION}

In this research, the characteristics of limestone and anthracite were analysed in terms of their elemental compositions, surface morphology and functional groups. The results of each analysis are discussed as follows.

\section{A. X-Ray Diffraction (XRD) and X-Ray Fluorescence (XRF) Analysis}

XRD analysis was used to identify the crystalline material and mineralogy of materials in accordance to ASTM S5357-03. Fig. 1 and Fig. 2 present the XRD patterns of raw limestone and anthracite coal, respectively. The presence of $\mathrm{CaCO}_{3}$ (ICDD No: 01-089-1304), as a predominant phase of limestone, is shown in Fig. 1.

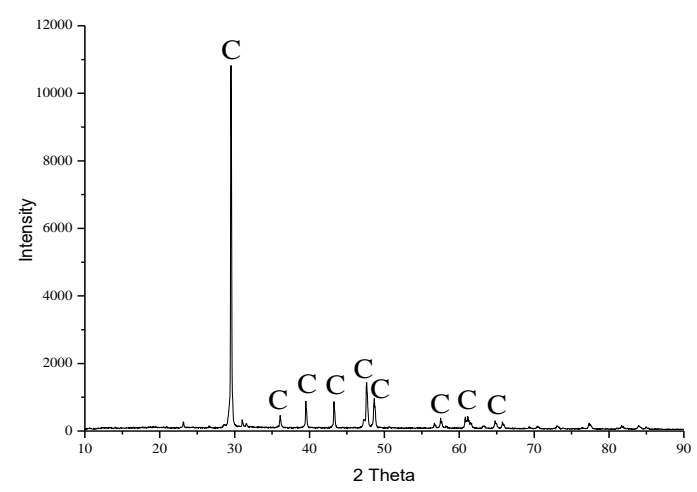

Fig. 1. X-ray diffractograms pattern of limestone.

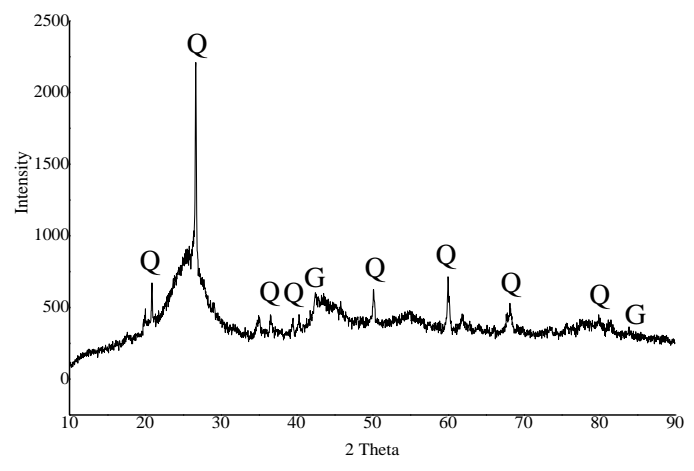

Fig. 2. X-ray diffractograms pattern of anthracite coal.

Calcite, which is consist of alternating $\mathrm{Ca}^{2+}$ and $\mathrm{CO}_{3}{ }^{2-}$, generates polar and hydrophilic surfaces that interact through electrostatic interaction and hydrogen bonding [15]. Electrostatic interaction occurs between calcium at the surface (positive charge) and oxygen in hydroxyl (negative 
charge). Hydrogen bonding occurs between oxygen in the calcite surface (negative charge) and hydrogen in the hydroxyl group (positive charge) [16]. [17] stated that a negative charged surface has the potential to develop a number of adsorption mechanisms, such as instance cation bridging, hydrogen bond and Van der Waals interaction. A positive charged surface can create adsorption interactions, such as hydrogen bonding, chelation and electrostatic interaction. Thus, this particular characteristic in limestone is suitable to immobilise charge ontaminants during adsorption [18]. The presence of $\mathrm{CaCO}_{3}$ in limestone increases the removal of $\mathrm{Fe}$ and $\mathrm{Mn}$ through metal precipitation [10]. The results of XRF analysis demonstrate that limestone contains $\mathrm{Ca}, \mathrm{Mg}, \mathrm{Si}$ and $\mathrm{Al}$ in the form of oxide concentrations of $54.83 \%$ (equivalent to $97.91 \% \mathrm{CaCO}_{3}$ ), $0.87 \%, 0.86 \%$ and $0.16 \%$, respectively. $\mathrm{CaCO}_{3}(97.91 \%)$ is found in limestone, showing that limestone does not contain impurities and can be classified as a pure limestone [19].

As shown in Fig. 2, the anthracite coal originates from quartz (ICDD No: 01-089-8935) and graphite (ICDD No: 01-075-2078) crystalline phases. Quartz appearing at $37.20^{\circ}$ is assigned as calcium silicate [12]. The main element present in anthracite is carbon. XRF analysis shows that anthracite contains more than $92 \%$ of carbon with low impurities, such as $6.224 \% \mathrm{SiO}, 0.618 \% \mathrm{Fe}_{2} \mathrm{O}_{3}, 0.496 \% \mathrm{SO}_{3}, 0.24 \% \mathrm{~K}_{2} \mathrm{O}$, $0.109 \% \mathrm{TiO}_{2}$ and other impurities. The high percentage of carbon content in anthracite indicates its hydrophobicity. Anthracite is formed under high pressure and temperature and possesses the characteristics, including well-ordered graphitic structure, high carbon content and high density compared with other coal sources [20]. Anthracite is a mineral with rich hydrophobic surface [21], [22]. Anthracite is suitable for the adsorption of hydrophobic/nonpolar portion of chemicals, such as natural organic matter, because of these characteristics. The affinity between nonpolar and other nonpolar materials is known as hydrophobic interaction [17]-[23].

\section{B. Fourier Transform Infrared (FT-IR)}

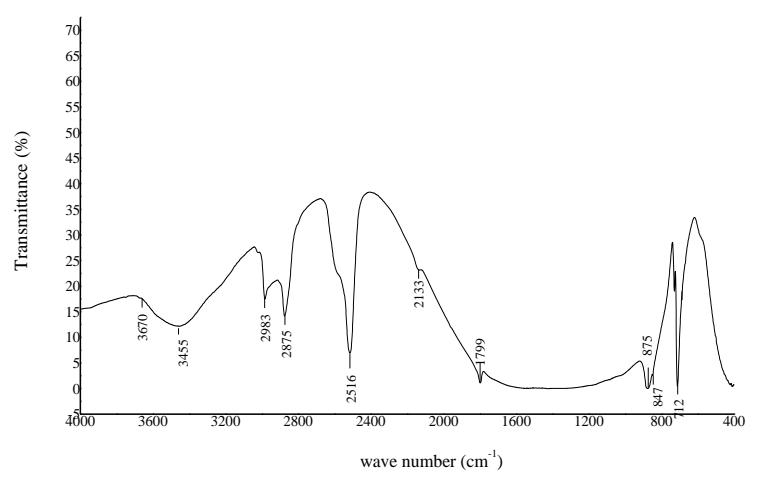

Fig. 3. FTIR spectrum of limestone

Figs. 3 and 4 show the FTIR analysis results of raw limestone and anthracite coal. As shown in Fig. 3, the 3455 $\mathrm{cm}^{-1}$ peak is located from $3200 \mathrm{~cm}^{-1}$ to $3500 \mathrm{~cm}^{-1}$ frequencies, corresponding to the strong stretching of hydroxyl group $(\mathrm{O}-\mathrm{H})$ in alcohol. The peak at $2516 \mathrm{~cm}^{-1}$ is observed. This peak matches with the hydroxyl $(\mathrm{O}-\mathrm{H})$ stretching of carboxylic acids in the frequency ranging from
$3300 \mathrm{~cm}^{-1}$ to $2500 \mathrm{~cm}^{-1}$. The characteristics of limestone composed of calcite are found at 875 and $712 \mathrm{~cm}^{-1}$ bands [24], [25]. The limestone used in this study has rich hydrophilic/polar functional groups. The hydroxyl group is known to possess the ability to attract heavy metal contaminants [26]. The presence of other polar groups, such as $\mathrm{C}=\mathrm{O}$ and carbonate groups, assists in the adsorption of cationic contaminants, such as heavy metals. The oxygen in the hydroxyl and $\mathrm{C}=\mathrm{O}$ is negatively charged, making it suitable site for the immobilisation of $\mathrm{Fe}$ and $\mathrm{Mn}$ ions via electrostatic interaction. The presence of small amount of $\mathrm{C}-\mathrm{H}$ and $\mathrm{C}-\mathrm{C}$ groups, which are known for their hydrophobic nature, positively influences the capability of limestone to adsorb contaminants via hydrophobic interaction [15].

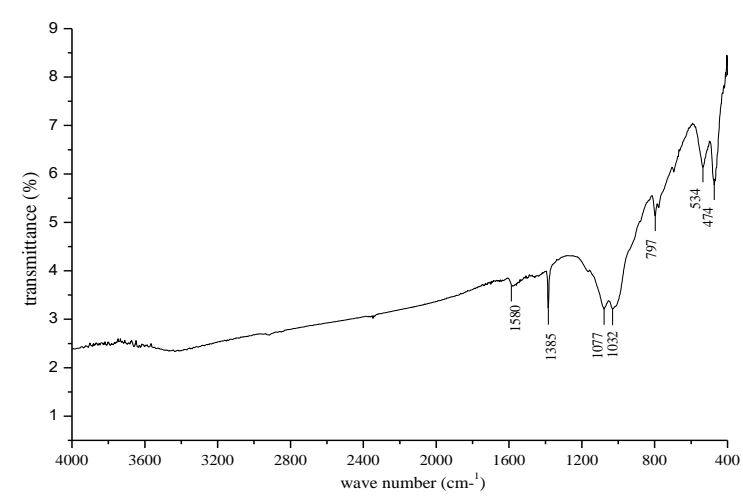

Fig. 4. FTIR spectrum of anthracite coal.

FTIR analysis shows that anthracite is a predominant coal in the functional group of aromatics, as shown in Fig. 4. The band at $1580 \mathrm{~cm}^{-1}$ is attributed to the $\mathrm{C}=\mathrm{C}$ stretching of an aromatic ring. A functional group of an alkane with medium $\mathrm{C}-\mathrm{H}$ bending is detected at $1385 \mathrm{~cm}^{-1}$. Primary alcohol with C-O strong stretching appears at $1077 \mathrm{~cm}^{-1}$. The functional group of alkyl aryl ether with strong stretching C-O overlaps the amine group with medium $\mathrm{C}-\mathrm{H}$ stretching at the 1032 $\mathrm{cm}^{-1}$ band. At the $797 \mathrm{~cm}^{-1}$ band, the alkene compound with medium bending of $\mathrm{C}=\mathrm{C}$ overlaps $\mathrm{C}-\mathrm{H}$. Shi et al., 2011 reported that anthracite has a major functional group of aromatic C-O, aromatic C-C and aromatic C-H [12]. They found that the quantitatively estimated functional group shows the aromatic functional group in descending order; C-C $(69.9 \%)>$ C-H $(29.6 \%)>$ C-O $(1.4 \%)$. The functional groups present on anthracite surface are mostly hydrophobic groups (C-C, C-H) [22]. The existence of hydrophilic functional group $(\mathrm{C}-\mathrm{O})$ is significant. Thus, anthracite can be used as an adsorbent to immobilise organic and inorganic contaminants.

\section{Field Emission Scanning Electron Microscopy (FESEM) Analysis (FT-IR)}

The surface structures of limestone and anthracite are shown in Fig. 5 and Fig. 6. Calcite has a smooth surface, various irregular shapes and with some cracks on the adsorbent surface at room temperature. The SEM image of limestone sample (Fig. 5) shows the crack between the connection of calcites and some cracks within the crystal on surface morphology. The crack can enlarge and a new crack can be produced with the increase in temperature. The pore appears in limestone because of $\mathrm{CaO}$, which agrees well with the XRF result, as shown in [14]. Hakim et al., (2017) 
indicated that pore and crack are directly proportional to temperature [15]. By contrast, various sizes of nonuniform irregular flakes with uneven texture are found on the surface structure of anthracite coal (Fig. 6). Some fragments and scraps appear on the anthracite coal surface.

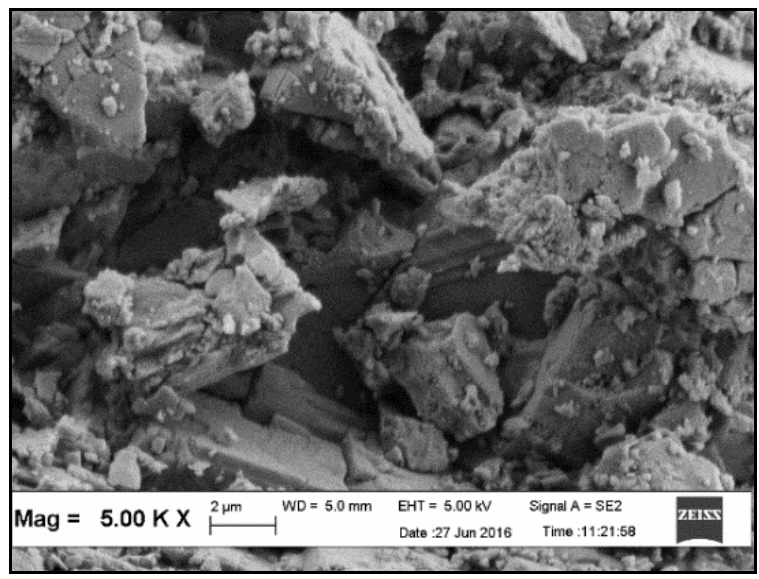

Fig. 5. Surface morphology of limestone.

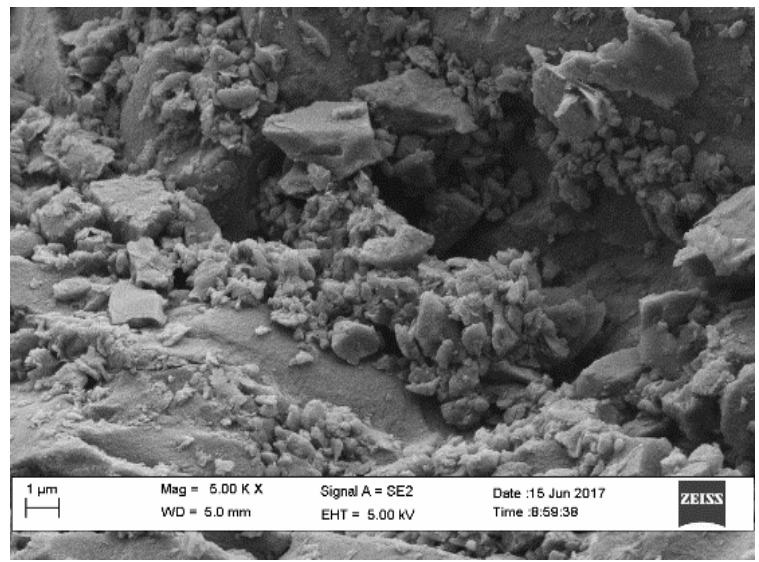

Fig. 6. Surface morphology of anthracite coal.

\section{CONCLUSION}

Limestone and anthracite are suitable as good adsorbents, and the differences in their characteristics enable them to adsorb different types of adsorbate. Limestone has rich hydrophilic groups $(\mathrm{O}-\mathrm{H}$ and $\mathrm{C}=\mathrm{O})$ and has the capability to adsorb $\mathrm{Fe}$ and $\mathrm{Mn}$. The functional groups present on the anthracite surface are mostly hydrophobic groups (C-C and $\mathrm{C}-\mathrm{H})$, which are beneficial for adsorbing organic compounds [21]. Regarding the limestone characteristics, its high carbonate content creates an alkaline condition for contaminated groundwater and increases the removal of $\mathrm{Fe}$ and $\mathrm{Mn}$ in water samples [10]. Therefore, the proposed media, limestone and anthracite are good media as filter, as limestone is good to remove heavy metals and anthracite is good to remove organic matter. Thus, the two adsorbents can be used as alternatives to treat groundwater.

\section{CONFLICT OF INTEREST}

The authors declare no conflict of interest.

\section{AUTHOR CONTRIBUTIONS}

In this research, N.A.Akbar conducted the experimental works on the characteristic of limestone and anthracite coal. This author analysed data from characteristic study and wrote the journal paper in consultation with H.A.Aziz and M.N.Adlan.

H.A.Aziz involved in planning and supervised research work. He guided and corrected the analyzed data especially in XRF analysis. He also verified the result obtained from elemental analysis using numerical calculation.

M.N.Adlan checked the content of the presented paper. He also proof read this journal paper. H.A.Aziz and M.N.Adlan supervised the project. All authors had approved the final version.

\section{ACKNOWLEDGMENT}

The authors thank to Universiti Teknologi MARA, Cawangan Pulau Pinang for the financial support for the payment fee of this paper. The authors would like to thank the School of Civil Engineering, Universiti Sains Malaysia under the Long-term Research Grant Scheme (LRGS) under Protection of Drinking Water for Society for the financial support in completing research

\section{REFERENCES}

[1] J. Hoslett, T. M. Massara, S. Malamis, D. Ahmad, I. Boogaret, E. Katsou, and H. Jouhara, "Surface water filtration using granular media and membranes: A review," Science of the Total Environment, vol. 639, pp. 1268-1282, 2018.

[2] E. A. H. Tan, A. W. Chew, and A. W.-K. Law, "Deployment of recyclable polycarbonate as alternative coarse media in dual-media rapid filters," Energy Procedia, vol. 143. pp. 475-480, 2017.

[3] S. Hussain, H. A. Aziz, M. H. Isa, M. N. Adlan, and F. A. H. Asaari, "Physico-chemical method for ammonia removal from synthetic wastewater using limestone and GAC in batch and column studies," Bioresource Technology, vol. 98. pp. 874-880, 2007.

[4] S. A. Chaudhry, T. A. Khan, and I. Ali, "Adsorptive removal of $\mathrm{Pb}$ (II) and $\mathrm{Zn}$ (II) from water onto manganese oxide-coated sand: Isotherm, thermodynamic and kinetic studies," Egyptian Journal of Basic and Applied Sciences, vol. 3.pp. 287-300, 2016.

[5] H. A. Aziz, M. N. Adlan, and K. S. Ariffin, "Heavy metals (Cd, Pb, Zn, $\mathrm{Ni}, \mathrm{Cu}$ and $\mathrm{Cr}(\mathrm{III})$ ) removal from water in Malaysia: post treatment by high quality limestone," Bioresource Technology, vol. 99. pp. 1578-83, 2008.

[6] H. A. Aziz, N. Othman et al., "Removal of copper from water using limestone filtration technique determination of mechanism of removal," Environment International, vol. 26. pp. 395-399, 2001.

[7] H. A. Aziz and P. G. Smith, "Removal of manganese from water using crushed dolomite filtration technique," Water Research, vol. 30, pp. 489-492, 1996.

[8] S. E. Ghazy and A. H. Ragab, "Removal of copper from water samples by sorption onto powdered limestone," vol. 14, pp. 507-514, 2007.

[9] I. Labastida, M. A. Armienta, R. H. Lara-Castro, A. Aguayo, O. Cruz, and N. Ceniceros, "Treatment of mining acidic leachates with indigenous limestone, Zimapan Mexico," Journal of Hazardous Materials, vol. 262, pp. 1187-95, 2013.

[10] H. A. Aziz and P. G. Smith, "The influence of $\mathrm{pH}$ and coarse media on manganese precipitation from water," Water Research, vol. 26, pp. 853-855, 1992.

[11] Malaysia Standard, "Drinking water quality requirement," Department of Standard Malaysia, 2010.

[12] X. Shi, H. Fu, Y. Li, J. Mao, S. Zheng, and D. Zhu, "Impact of coal structural heterogeneity on the nonideal sorption of organic contaminants," Environmental Toxicology and Chemistry, vol. 30, pp. 1310-1319, 2011.

[13] R. Tseng, "Physical and chemical properties and adsorption type of activated carbon prepared from plum kernels by $\mathrm{NaOH}$ activation," vol 147, pp. 1020-1027, 2001.

[14] Y. Zhang, Q. Sun, and J. Geng, "Microstructural characterization of limestone exposed to heat with XRD, SEM and TG-DSC," Materials Characterization, vol. 134, pp. 285-295, 2017. 
[15] S. S. Hakim, M. H. M. Olsson, H. O. Sorensen, N. Bovet, J. Bohr, and R. Feidenhans, "Interactions of the calcite surface with organic compound Structure and behavior at mineral-organic interface," Scientific Report, vol. 7, pp. 1-11, 2017.

[16] M. Wolthers, D. Tommaso, Z. Du, and N. H. D. Leeuw, "Calcite surface structure and reactivity: molecular dynamics simulations and macroscopic surface modelling of the calcite," Physical Chemistry Chemical Physic, vol. 14, pp. 15145-15157, 2012.

[17] A. Philippe and G. E. Schauman, "Interactions of dissolved organic matter with natural and engineered inorganic colloids: A review," Environmental Science and Technology, vol. 48, pp. 8946-8962, 2014

[18] T. Yang, R. He, G. Nie, W. Wang, G. Zhang, Y. Hu, and L. Wu, "Creation of hollow calcite single crystals with CQDs: Synthesis, characterization and fast and efficient decontamination of Cd (II)," Scientific Report, vol. 8, p. 17603, 2018.

[19] C. Mitchell. (2011). High purity limestone quest. Industrial Minerals. [Online]. Available: http://nora.nerc.ac.uk/15887/1/Reconnaissance_assessment_of_high-p urity_limestone_plus_references.pdf

[20] N. Byamba-ochir, W. Geun, M. S. Balathanigaimani, and H. Moon, "Applied surface science highly porous activated carbons prepared from carbon rich Mongolian anthracite by direct $\mathrm{NaOH}$ activation," Applied Surface Science, vol. 379, pp. 331-337, 2016.

[21] W. Xia, "The effect of heating on the wettability of lignite," Energy Source, vol. 38, pp. 3521-3526, 2016.

[22] W. Xia and G. Xie, "Comparison of surface properties of anthracite coals before and after high temperature heating process," Physicochemical Problems of Mineral Processing, vol. 51, 2015.

[23] D. Ahmad, I. Boogaet, J. Miller, and R. Presswell, "Environmental effects hydrophilic and hydrophobic materials and their applications," Energy Sources, vol. 40, pp. 2686-2725, 2018.

[24] A. Sdiri, T. Higashi, T. Hatta, F. Jamoussi, and N. Tase, "Mineralogical and spectroscopic characterization, and potential environmental use of limestone from the Abiod formation, Tunisia," Environmental Earth Sciences, vol. 61, pp. 1275-1287, 2010.

[25] S. Gunasekaran and G. Anbalagan, "Spectroscopic characterization of natural calcite minerals," Spectrochimica Acta - Part A: Molecular and Biomolecular Spectroscopy, vol. 68, pp. 656-664, 2007.

[26] G. Rangel-Porras, J. B. Garcia-Magno, and M. P. Gonzalez-Monoz, "Lead and cadmium immobilization on calcitic limestone materials," Desalination, vol. 262, pp. 1-10, 2010.

Copyright $\odot 2021$ by the authors. This is an open access article distributed under the Creative Commons Attribution License which permits unrestricted use, distribution, and reproduction in any medium, provided the original work is properly cited (CC BY 4.0).

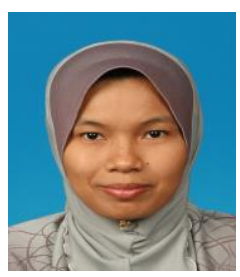

N. A. Akbar was born in Kedah, Malaysia on 31st Dec. 1980. She graduated in BSc. in civil engineering at Universiti Technology MARA, Malaysia in 2004 and the M. Eng (environmetal management) from University Technology Malaysia, Skudai Johor Bharu, Malaysia in 2006. After that she works as a lecturer at University Technology MARA, Penang, Malaysia. Then, she continued her PhD on advanced groundwater treatment technology and graduated from University Science Malaysia in 2019. Currently, she is a senior lecturer at Faculty of Civi Engineering, Universiti Teknologi MARA, Cawangan Pulau Pinang, Malaysia. She was interested in water and wastewater treatment processes, groundwater treatment technology, advanced oxidation process, adsorption process and water quality monitoring. She had almost more than 10 years' experience in teaching subject related to water resources and environmental engineering.

She is also registered with Board of Engineer Malaysia (BEM) and Malaysian Water Association (MWA) and Malaysian Stormwater Management Organization (MSO).

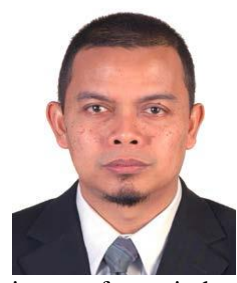

H. A. Aziz obtained his $\mathrm{PhD}$ degree in civil engineering (environmental engineering) from the University of Strathclyde in Scotland in 1992.

Currently, he is a professor in environmental engineering in the School of Civil Engineering and the Head of the Solid Waste Management Cluster, Universiti Sains Malaysia. His research focuses on alleviating problems associated with water pollution issues from industrial wastewater discharges and from solid waste management via landfilling, such as landfill leachate. He also has strong interest in biodegradation and bioremediation of oil spills and also in noise pollution.

Professor Aziz is the editor-in-chief of the International Journal of Scientific Research in Environmental Sciences (IJSRES), and the Managing Editor of the International Journal of Environment and Waste Management (IJEWM) and International Journal of Environment and Waste Management (IJEE). He has published over 200 refereed articles in international journals and proceedings. The details of his published works are available through Researcher ID: F-6836-2010 and SCOPUS ID: 7005960760.

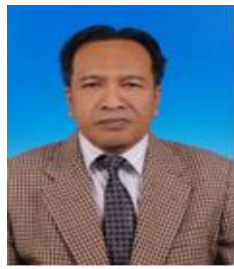

M. N. Adlan was born in Perak, Malaysia on 3rd April 1953. He obtained BSc in civil engineering from The Polytechnic of Central London in 1980, the MSc in water and waste engineering from Loughborough University in 1989 and the $\mathrm{PhD}$ from University of Newcastle Upon Tyne in 1998.

Prior to joining University Sains Malaysia (USM) in 1991, he has vast industrial experience with Public Works Department of Malaysia and attachment with Samsung Construction Co. Ltd., South Korea in 1983 to 1984 . The last post he held prior to joining USM was a district engineer with Perak Water Board.

Prof Adlan is Program Leader of a Long Term Research Grant funded by the Ministry of Education Malaysia and Head of Water Security Cluster (Science and Engineering Research Centre, USM). He is a professional engineer registered with the Board of Engineers Malaysia and Fellow of the Institution of Engineers Malaysia. He has been awarded with top cited paper in Desalination in 2013. He has published his papers in several ISI journals such as Chemical Engineering Journal, Bioresourse Technology, Desalination, Water Resource Management etc. 